\title{
ROLE OF SOCIAL DETERMINANTS OF HEALTH IN PSYCHOLOGICAL DISTRESS AND READINESS FOR ONLINE LEARNING AMONG COLLEGE FILIPINO STUDENTS DURING THE COVID-19 PANDEMIC: A PILOT STUDY
}

\author{
Rey Jan Pusta, Cherril Mina, Bonnie Abanid, \\ Don Miguel Nino Doromal and Ruel R. Billones* \\ Ateneo de Davao University, Philippines
}

\begin{abstract}
Due to the COVID-19 pandemic, educational institutions in the Philippines rapidly introduced widespread online learning to ensure safety of learners. The purpose of this study was to explore the possible relationship of social determinants of health with COVID-19 specific psychological distress and the readiness of Filipino students to learn online. Researchers conducted an online survey of 30 college students from the Psychology program of Ateneo de Davao University in Davao City, Philippines. Results showed that students experienced mild (53.3\%) to severe (36.7\%) levels of COVID-19 specific psychological distress. COVID-19 specific psychological distress and readiness for online learning was not significantly correlated, $r(30)=-.18, p=.35$. Among social determinants of health, only living with family members was significantly associated with readiness for online learning, $r(30)=-.37, p=.046$. These findings showed promising findings on how social determinants of health may be associated with distress and online learner readiness during a global pandemic. Future studies may elaborate on the subjective experiences of students. Finally, this pilot study serves as a basis for the development of school programs that address students' mental health and promote online learning readiness of students who are experiencing unique learning circumstances.
\end{abstract}

Keywords: COVID-19, readiness for online learning, psychological distress, social determinants of health, college students

The World Health Organization (WHO) acknowledged fear as a universal response in the COVID-19 pandemic experience (WHO, 2020a). The world is confronted by drastic changes due to safety precautions that necessitated working and doing school from home. Facing this unprecedented circumstance, WHO (2020a) compelled the public to not only look after one's physical well-being but also one's mental health. On January 30, 2020, WHO declared the outbreak to be a public health emergency of international concern (Sohrabi et al., 2020). In comparison with Severe Acute Respiratory Syndrome (SARS) and Middle East Respiratory Syndrome (MERS), COVID-19 has spread more rapidly due in part to increased global economic trade using major international airports and the interconnected transit systems (Peeri et al., 2020). From Wuhan, the virus spread throughout China reaching the rest of the countries of the world (Peeri et al., 2020). By the end of the first quarter of 2020, Dr. Tedros Adhanom Ghebreyesus, the Director General of the World Health Organization, declared the outbreak as a pandemic (WHO, 2020a).

Schools all over the world were adversely affected and had to either close or adapt to the new situation. School closures affected almost $70 \%$ of the world's student population, many of whom were 
affected by local school lockdowns or closures (UNESCO, 2020). Meanwhile in March 2020, the Department of Education (DepEd) of the Philippines initially stated the continuation of classes despite the pandemic (Mendoza, 2020). The Commission on Higher Education (CHED), the Philippine government agency for colleges and universities, stated that the present curriculum needs to be revised to address the learner's context (Toquero, 2020). Both DepEd and CHED ordered distance learning, e-learning, and other alternatives in lieu of face-to-face classroom instruction (Commission on Higher Education, 2020; Mateo, 2020).

There is a question of whether stakeholders across various sectors were ready for the sudden and sweeping impact of the pandemic. As previously mentioned, education is one of those that have been severely affected by the current circumstances. A preliminary survey of Filipino students revealed that they were not ready for engaging in an e-learning platform (Clemen et al., 2021). In the same survey, a lack of financial capacity and equipment barred students coming from mostly low-income households from this modality. In the context of education, there is then a revelation of the economic impact brought about by the pandemic on learners (Abiad et al., 2020).

There are rising concerns that aside from education, the mental health of students is affected. Quarantines, closure of recreational spaces and events affect most especially young adolescents. Their need to interact and mingle with peers which is necessary to their development to foster their identity and purpose are hampered, increasing the risk for mental health problems (Noguchi, 2020). The disruption of normality also affects their mental health. Traditionally, their school life occupied a significant portion of their time which was a significant source of their growth (Craw, 2020). It has been predicted that following the COVID-19 pandemic, there will be a surge in mental health disorders as a consequence (Kanter \& Manbeck, 2020).

Social factors are revealed to contribute to the mental distress and unpreparedness of students for online learning. In response to the provision of a more comprehensive framework for preventing and treating diseases, the World Health Organization (WHO) conceptualized the Social Determinants of Health (SDH). These factors include socioeconomic and political contexts such as public policy and cultural values, and socioeconomic positions. These positions are reflected in educational attainment, occupation, and income. They all impact health outcomes (Solar \& Irwin, 2010). Recent findings have shown the link between SDH and mental health indices (Silva, Loureiro, \& Cardoso, 2016). The current pandemic exposes the role SDH factors to unpack social forces such as income disparity, family dynamics, among others to affect mental health and ability of the students to learn during a health crisis (Mental Health Foundation, 2020).

\section{Online Learning Readiness}

Online learning became the platform of education during the pandemic. Learners' experiences and demographics impact learning readiness exposed during the move to the online platform that exposed challenges to learning. Factors such as access to the online platform exposed the economics of those who can afford prepaid internet load or internet connectivity measured by hours and those who are unable to. Another challenge was the unfamiliar materials uploaded online, which caused real challenges to learning readiness (Marcial et al., 2015). Self-efficacy is defined as the belief in one's 
ability (Bandura, 1982), while motivation is what enacts or sustains one's behaviors, in this case, learning online (Wigfield \& Eccles, 2002). Yet these external hurdles to achieve learning were countered by these two factors, and this finding remained constant regardless of the platform of learning. (Francis et al., 2019). One study, however, challenged this increase in self-efficacy and motivation when they saw the decrease of students' performance in Indonesia (Irawan et al., 2020).

\section{Psychological Distress and COVID-19}

The losses due to closures of businesses that were source of families' livelihood, the loss of lives, and the loss of social connection have impacted the population's mental health and wellbeing (Cohen \& Kupferschmidt, 2020). The isolation of young people and those who struggle to access basic necessities of life such as food pose high psychological risk and harm (Razai, 2020). The psychological distress being experienced by young people is reflected in many of the context-based psychological measures of disorders experienced by Filipinos like depression and anxiety (Montano \& Acebes, 2020; Tee et al., 2020).

\section{Social Determinants of Health}

There is an increasing trend toward looking into how social determinants are contributory toward the improvement or detriment of mental health (Myer et al., 2008). One example of this is the role of food security and its influence on psychological distress and perceived mental health status (Becerra \& Becerra, 2020). Other factors such as ethnicity, occupational prestige, and annual family income show an inverse relationship with distress. Social capital, as a product of these factors and more, has a complex relationship with mental health (Song, 2011). In the context of the pandemic, it becomes a question, then, on which determinants are subject to further examination.

It has been suggested that physical proximity to COVID-19 outbreak epicenters have a significant relationship. In China, S. Zhang and colleagues (2020) found a psychological version of a ripple effect and a typhoon effect in the levels of psychological distress among individuals. Yáñez et al. (2020) found a ripple effect only when examining the epicenter of the COVID-19 crisis in Peru. Strained family dynamics may also contribute to the vulnerabilities revealed by the consequences of the pandemic. Quarantine measures may exacerbate tensions in the family, resulting in domestic violence (Usher et al., 2020). History of health also appears to be linked to increased anxiety and depression in light of the COVID-19 pandemic (Mazza et al., 2020). There is utility in examining whether these same results would reflect in the Philippine locale. These would then be the target for intervention by mental health professionals and other stakeholders. The escalation of abuse in homes is another social determinant worthy of investigation during this pandemic (Duncan, 2020).

These recent events necessitate the urgency to address the issues surrounding learning readiness and COVID-19 distress among Filipino students. This article aims to answer the following questions:

1. What are the levels of psychological distress among Filipino college students during the COVID-19 pandemic? 


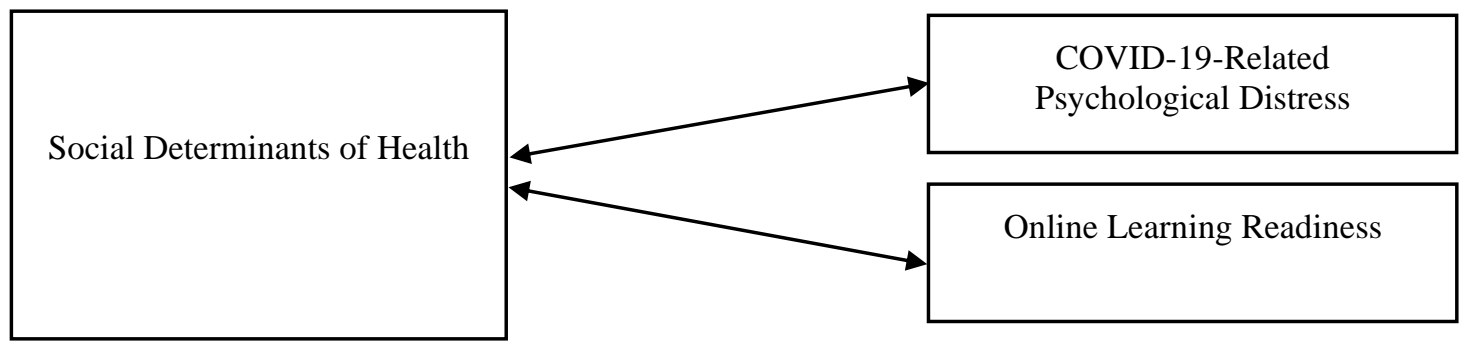

\section{Conceptual Framework}

Figure 1. Conceptual framework showing the hypothesized relationship between Social Determinants of Health with COVID-19-Related Psychological Distress and Online Learning Readiness.

2. Is there a significant relationship between social determinants of health and online learning readiness of Filipino college students?

3. Is there a significant relationship between social determinants of health and psychological distress of Filipino college students?

\section{Methodology}

This pilot study utilized a cross-sectional survey design to determine the levels of social determinants of health, COVID-19-specific psychological distress, and readiness for online learning. Data used for the analysis were gathered using online self-report instruments. These were administered online to respondents as survey questionnaires. Prior to answering the online survey forms, participants read preliminary information and their rights related to the study. Those who consented to participating then answered the online questionnaires. Equal access was provided as all participants were invited by the researchers. Descriptive statistics provide a summary of the data, while correlational analyses were used to examine the relationships between variables of interest. As a pilot study, this study does not aim to provide generalizable findings. It was conducted to provide a backdrop for follow-up studies. These studies may come in the form of qualitative interviews to corroborate the findings or quantitative surveys that may increase the generalizability of the findings.

\section{Locale of the Study}

The study was conducted online for college students at a university in Davao City, Philippines. Davao City has a population of 1,632,991. As of 2019, the city hosts 53 public and private universities and colleges, with 88,228 who were enrolled for the school year 2018-2019 (Philippine Statistics Authority, 2019). 


\section{Participants}

The participants of the study were 30 college students from the Psychology program of Ateneo de Davao University. They were at least 18 years old and enrolled in a course that utilized an online learning platform using an online software such as Google Classroom. Those who were planning to be in an online platform were also included in the study.

\section{Sampling Method}

The pilot study utilized a nonprobability sampling technique to identify at least 30 participants. A software program (G*Power) was used to approximate a sample size with sufficient statistical power. Using Psychological Distress and Online Learning Readiness as the primary variable, with 80 percent power and a correlation coefficient of 0.3 , a sample size of 23 suffices for the inferential statistic used. In particular, the researchers utilized convenience sampling, whereby a group of willing participants were selected from the population until the desired sample size was reached. Due to the nature of the sampling size and method used, the study is not expected to generate results generalizable to the population.

\section{Instruments}

Social Determinants of Health. A survey questionnaire was constructed by the researchers to include the social determinants of health (SDH). These variables were reflected in the demographic profile of the participants including age, gender, area raised, area of residence, having a health insurance plan, presence of positive COVID-19 results the respondent's city and smaller administrative units such as the barangay (county), sitio (town), purok (suburb), health history of sickness prior to six months, assessment of family member with chronic disease, family's average monthly income, and internet access. Areas of residence and location where they were raised had the classification of whether these locations were urban or rural areas. Presence of COVID-19 cases were determined by asking whether a confirmed case was reported in their city of residence and in their sitio, purok, or barangay. Presence in these areas thus implied closer proximity of a COVID-19 case for the participant. Average monthly income was self-reported from both parents. Information about access to the internet was obtained by asking whether the student had an internet connection that can satisfactorily enable access to class materials and communicate with classmates and instructors.

Psychological Distress. Psychological distress was measured using the Covid-19 Peritraumatic Distress Index (CPDI). The CPDI was a 24-item questionnaire that measures the frequency of specific phobias, cognitive changes, physical symptoms, and other manifestations of psychological distress within the context of the current pandemic (Qiu et al., 2020). Manifestations of distress range from "Never" to "Most of the time" on a 5-point scale. The CPDI score was obtained by summing all items and adding four points. Scores above 52 indicate severe distress, scores between 28 to 51 indicate mild to moderate distress, and scores below 28 indicate a normal level of distress. One sample item was "I collect information about Covid-19 all day. Even if it's not necessary, I can't stop myself". Results from the study's data show very good internal consistency $(\alpha=.91)$. Permission was obtained from the authors (Qiu et al., 2020) to utilize this questionnaire for the study. 
Readiness for Online Learning. Self-efficacy was measured through the online learning readiness scale (OLRS) developed by Hung, Chou, Chen, and Own (2010). The scale was originally developed to measure learner readiness for online learning. The scale contained five factors: computer/internet self-efficacy, self-directed learning, learner control, motivation for learning, and onlinecommunication self-efficacy. Eighteen items were measured on a five-point scale, ranging from "Strongly disagree" to "Strongly agree"). Scores for each factor were determined by summing up the scores of the items. Sample items include "I feel confident in using the Internet (Google, Yahoo) to find or gather information for online learning" and "I feel confident in using online tools (email, discussion) to effectively communicate with others". Based on the present study's data, the following reliability statistics were calculated: computer/internet self-efficacy $(\alpha=.71)$, self-directed learning $(\alpha=.51)$, learner control $(\alpha=.40)$, motivation for learning $(\alpha=.60)$, and online communication selfefficacy ( $\alpha=.44)$. Insufficient interitem consistency among the items was found to be contrary to the published reliability statistics for the questionnaire. One possible reason may be the contribution of sampling error as the study had a small sample size. Permission was obtained from the authors (Hung et al., 2010) to utilize this questionnaire for the study.

\section{Research Procedure}

The first step taken was to secure permissions from the university's psychology department and academic club. Authorizations to utilize the instruments in the study were also obtained. Once these were secured, researchers sought the recommendations and approval from the department which served as the ethical board. The volunteers identified were given a link. The study utilized Google Forms, so the link provided to volunteers contained a starting page that provided a background of the study and an informed consent. The researchers also included a feedback form in the last page should they have any suggestions or concerns. Informed consent was obtained prior to data collection.

The data were then encoded into a spreadsheet program and processed via IBM SPSS Version 25. Descriptive statistics such as frequencies and percentages were reported. Inter-item reliability was assessed to obtain a Cronbach's alpha of the CPDI scales. A partial correlation controlling for age and sex was made to determine if there was a significant relationship between psychological distress and readiness for online learning. Pearson correlation tests were used to ascertain the relationships among SDH with Psychological Distress, and Readiness for Online Learning. Finally, Pearson Product Moment correlation tests were also conducted among the OLRS subscales to ascertain the interitem correlation of the items. These were then tabulated for presentation.

\section{Ethics Statement}

The study was approved by the Department of Psychology, Ateneo de Davao University, Davao City.

\section{Results}

Demographic Characteristics of the Participants. The study included 30 participants for analysis. The participants had a mean age of 20 years old $(\mathrm{SD}=2)$. Most of them were female $(\mathrm{n}=21)$ and the rest 
were male $(n=8)$ except for one who did not wish to specify their sex. Participants mostly grew up in urban areas $(\mathrm{n}=22)$ with eight growing up in rural areas. At present, many remained as residents of urban areas $(n=24)$ with the rest still residing in rural areas $(n=6)$. In terms of living arrangements, 25 participants lived with immediate or extended family members.

Regarding their health and economic status, 12 participants indicated having been sick in the last six months, with 16 saying no. Two participants preferred not to answer the item. The majority did not report having a chronic health condition $(n=26)$, while four did not wish to answer the item. Almost half of the participants did not report having availed of a health insurance plan $(n=14)$ but was closely followed by those who did have health insurance $(n=13)$; three of them preferred not to indicate their health-insurance status. Many participants $(n=10)$ were not sure of their average family income, while some $(n=6)$ preferred not to disclose this information. The lowest income bracket (PHP 40,000 and below) included 6 participants, while the highest bracket (250,000 and above) included one participant. Three participants belonged to the 'PHP 40,000 to 59,999' bracket, and two participants each belonged to the 'PHP 60,000 to 99,999 ' and ' 100,000 to 249,999 ' brackets.

In terms of their connectivity, many utilized only home internet services such as DSL or Broadband (n $=18$ ), and this was followed by those who used both home internet services and mobile phone data services $(n=11)$. Only one participant used mobile phone data exclusively to access the internet. Many students combined using a laptop and a smartphone $(\mathrm{n}=22)$ for accessing the internet. Few students use a smartphone exclusively $(n=4)$ or a laptop exclusively $(n=2)$. One participant used a combination of a laptop, smartphone, and desktop computer. Another used a laptop, tablet computer, and a desktop computer. In terms of having self-reported fast and reliable internet, many $(n=23)$ did not find this to be the case.

Levels of Psychological Distress. Table 2 illustrates the frequency and percentage distributions of students in terms of their COVID-19-specific psychological distress levels. Half of the sample (53.3\%) experienced mild distress levels in connection to the COVID-19 pandemic. Approximately a third of participants $(36.7 \%)$ experienced severe levels of distress. It appears that a minority of individuals did not experience elevated distress levels (10\%).

Table 1 (continues onto the next page)

Sociodemographic Characteristics of the Study Participants

\begin{tabular}{|c|c|c|c|}
\hline Variable & Response & Frequency & Percentage of Total \\
\hline \multirow[t]{3}{*}{ Sex } & Male & 8 & $27.6 \%$ \\
\hline & Female & 21 & $72.4 \%$ \\
\hline & Prefer not to say & 0 & $0.0 \%$ \\
\hline \multirow{2}{*}{$\begin{array}{l}\text { Area raised in urban } \\
\text { setting }\end{array}$} & No & 8 & $26.7 \%$ \\
\hline & Yes & 22 & $73.3 \%$ \\
\hline \multirow{2}{*}{$\begin{array}{l}\text { Area of residence in } \\
\text { urban setting }\end{array}$} & No & 6 & $20.0 \%$ \\
\hline & Yes & 24 & $80.0 \%$ \\
\hline \multirow{2}{*}{$\begin{array}{l}\text { Living with immediate or } \\
\text { extended family member }\end{array}$} & No & 5 & $16.7 \%$ \\
\hline & Yes & 25 & $83.3 \%$ \\
\hline
\end{tabular}




\begin{tabular}{|c|c|c|c|}
\hline \multirow{3}{*}{$\begin{array}{l}\text { Sick for the last } 6 \\
\text { months }\end{array}$} & No & 16 & $57.1 \%$ \\
\hline & Yes & 12 & $42.9 \%$ \\
\hline & Unsure & 0 & $0.0 \%$ \\
\hline \multirow{2}{*}{$\begin{array}{l}\text { With chronic health } \\
\text { condition }\end{array}$} & No & 26 & $86.7 \%$ \\
\hline & Prefer not to say & 4 & $13.3 \%$ \\
\hline \multirow[t]{3}{*}{ COVID case in City } & No & 1 & $3.4 \%$ \\
\hline & Yes & 28 & $96.6 \%$ \\
\hline & Unsure & 0 & $0.0 \%$ \\
\hline \multirow{3}{*}{$\begin{array}{l}\text { COVID case in sitio, purok, } \\
\text { barangay }\end{array}$} & No & 10 & $43.5 \%$ \\
\hline & Yes & 13 & $56.5 \%$ \\
\hline & Unsure & 0 & $0.0 \%$ \\
\hline \multirow[t]{3}{*}{ Health Insurance } & No & 14 & $51.9 \%$ \\
\hline & Yes & 13 & $48.1 \%$ \\
\hline & Unsure & 0 & $0.0 \%$ \\
\hline \multirow[t]{7}{*}{ Average family income } & Prefer not to say & 6 & $20.0 \%$ \\
\hline & PHP 40,000 below & 6 & $20.0 \%$ \\
\hline & 40,000 to 59,999 & 3 & $10.0 \%$ \\
\hline & 60,000 to 99,999 & 2 & $6.7 \%$ \\
\hline & 100,000 to 249,999 & 2 & $6.7 \%$ \\
\hline & 250,000 above & 1 & $3.3 \%$ \\
\hline & Unsure & 10 & $33.3 \%$ \\
\hline \multirow[t]{3}{*}{ Means of Internet Access } & $\begin{array}{l}\text { Home internet services } \\
\text { (DSL, Cable, } \\
\text { Broadband) }\end{array}$ & 18 & \\
\hline & $\begin{array}{l}\text { Home internet services } \\
\text { (DSL, Cable, } \\
\text { Broadband), Mobile } \\
\text { phone data services }\end{array}$ & 11 & \\
\hline & $\begin{array}{l}\text { Mobile phone data } \\
\text { services }\end{array}$ & 1 & \\
\hline \multirow[t]{5}{*}{ Devices for Internet Access } & $\begin{array}{l}\text { Desktop PC, Laptop } \\
\text { (Traditional, 2-in-1, } \\
\text { etc.), Smartphone }\end{array}$ & 1 & \\
\hline & $\begin{array}{l}\text { Laptop (Traditional, 2- } \\
\text { in-1, etc.) }\end{array}$ & 2 & \\
\hline & $\begin{array}{l}\text { Laptop (Traditional, 2- } \\
\text { in-1, etc.), Smartphone }\end{array}$ & 22 & \\
\hline & $\begin{array}{l}\text { Laptop (Traditional, 2- } \\
\text { in-1, etc.), Tablet, } \\
\text { Smartphone }\end{array}$ & 1 & \\
\hline & Smartphone & 4 & \\
\hline \multirow{2}{*}{$\begin{array}{l}\text { Proximity to nearby internet } \\
\text { source }\end{array}$} & No & 24 & $80.0 \%$ \\
\hline & Yes & 6 & $20.0 \%$ \\
\hline \multirow[t]{2}{*}{ Fast and reliable internet } & No & 23 & $76.7 \%$ \\
\hline & Yes & 7 & $23.3 \%$ \\
\hline
\end{tabular}


Table 2

Levels of Psychological Distress

\begin{tabular}{llcc}
\hline Variable & Levels & Frequency (f) & Percentage (\%) \\
\hline $\begin{array}{l}\text { Psychological } \\
\text { Distress }\end{array}$ & Normal & 3 & $10.0 \%$ \\
& Mild & 16 & $53.3 \%$ \\
& Severe & 11 & $36.7 \%$ \\
\hline
\end{tabular}

Normality of the Data. The normality of the data was also examined prior to conducting inferential tests. A visual inspection of the histograms for Online Learning Readiness and Psychological Distress show similarities to a normal curve. Shapiro-Wilk tests for normality show no significant deviation from the normal distribution for both Online Learning Readiness $(p=.650)$ and Psychological Distress $(p=.228)$.

Relationship between Social Determinants of Health, Readiness for Online Learning, and Psychological Distress. Living with family members appeared to be negatively associated with readiness for online learning, $r(30)=-.37, p=.046$. Others appear to display weak to moderate associations but were not statistically significant (see Table 3 ).

\section{Discussion}

The current pilot study aimed to present a sociodemographic profile of the participants and quantify their levels of psychological distress, along with determining the relationship between social determinants of health with psychological distress and online learning readiness. More females than males chose to participate in this study. Furthermore, most of the participants in the sample were also urban residents. As sex, gender, and residence are acknowledged as social determinants themselves, it must be noted that a diverse and well-proportioned sample is needed.

More than half of the students were also living with their immediate or extended family members. This is a typical arrangement for Filipino families, as they often have large families alongside child and family-centric value systems (Medina, 2001). As part of their social determinants of health, the researchers also found that many of them did not report illnesses six months before they were surveyed. Despite the threat of the pandemic, none of the participants reported having a chronic health condition and around half reported having health insurance. As of the time they were surveyed, many reported having a COVID-19 case in the city. Many of them also belonged to lower- to upper-middle income classes. Yet despite this, many of them struggled with not having a reliable and fast internet connection. These concerns, particularly on socioeconomic factors such as income and internet connection, are prevalent during the pandemic (Abiad et al., 2020). 
Table 3

Correlation results of Social Determinants of Health with Readiness for Online Learning and Psychological Distress

\begin{tabular}{lll}
\hline Variable & $\begin{array}{l}\text { Readiness for Online } \\
\text { Learning }\end{array}$ & Psychological Distress \\
\hline Sex & -.13 & .17 \\
Area raised in & .12 & -.16 \\
Area of residence & .05 & -.22 \\
Living with family members & $-.37 *$ & .13 \\
Sick for the last six months & .2 & .31 \\
With chronic health condition & .04 & .07 \\
Covid-19 case in city & .01 & -.14 \\
Covid-19 case in sitio, purok, or barangay & .1 & -.33 \\
Access to health insurance & -.01 & 0.14 \\
Proximity to nearby internet source & .17 & 0.1 \\
Fast and reliable internet & .32 & 0.2 \\
\hline
\end{tabular}

$* p<.05$

Psychological distress within the context of COVID-19 is mild (Table 2). The higher rate of psychological distress was observed among female students. These data are consistent with the longitudinal studies on evaluating the psychological distress among college students in general in the US college population (Sharp \& Theiler, 2018). This seems to suggest that pre-existing conditions that are gender-based to female students have been present prior to COVID-19 that predispose them to have a higher experience of psychological distress during the pandemic.

In general, only living with family members negatively correlated with online learning readiness (Table 3). This result seems to suggest the exposure of unresolved family issues. One family issue may be physical space. Demarcating study areas for learners in a confined physical structure poses challenges where every family member's event could take place in the same space as meals and entertainment. Another issue could be interpersonal. The handling of interpersonal relationships with other family members could create unnecessary tensions especially if they are unresolved and lingering relational dynamics. The limitations include lack of physical boundaries to demarcate workstations from family living areas. Working and learning from home create its own stresses that do not facilitate learning. (Dellosa, 2020). Some studies do not appear to indicate a relationship between the two constructs (Alkorashy \& Assi, 2016). A similar study by Ng and Confessore (2015) show a negative but non-significant relationship between living arrangements and learner autonomy. 
While the rest of the bivariate relationships were found to be non-significant, they still warrant discussion. For example, online learning readiness had a weak yet non-significant relationship with a fast internet connection and proximity to a nearby internet source. In the Philippine context, studies such as Estira (2020) found that socioeconomic status and diversity of electronic devices were significantly correlated with online learning readiness in a sample of Filipino college students. Callo and Yazon (2020) found that faculty and students in a Philippine state university were only somewhat ready for online learning. They also found that many respondents did not have access to devices such as laptops or desktop computers. The COVID-19 pandemic appears to have made apparent an obstacle in online education: access to devices that can connect to the internet and meet the educational requirements of the student. In a developing country such as the Philippines, this is especially highlighted as many Filipinos rely on mobile phones and with an estimated 67\% (73 million) of the population who have used the internet (Kemp, 2020).

COVID-19 Psychological Distress was also investigated to see if it correlated with certain social determinants of health. As mentioned, the results were also not significant. Yet it is notable that being sick in the past 6 months was associated with higher psychological distress. This may be due to fears that comorbidities may exacerbate COVID-19 symptoms. On another note, there was a negative association with psychological distress and proximity to a COVID-19 case. This is in contrast to findings that show a positive and significant relationship between them (Chen et al., 2020. This "ripple" or "eye of the typhoon" effect was seen in previous studies in addition to the aforementioned (Lai et al., 2020), where areas with more positive cases increase one's perceived personal danger, therefore raising distress levels. It could be that the respondents in the study were not distressed despite the presence of COVID-19 in their localities. Now that the pandemic has spread so extensively, it may be of more interest to examine whether students whose family or household members were infected had significantly higher psychological distress levels than other students.

\section{Conclusion}

The study found that, expectedly, many students among the sample were experiencing mild to severe psychological distress brought about by the pandemic. Based on a survey of certain social determinants of health, one that was relevant to the study was that many of them were struggling with an available, fast, and reliable internet connection. Several measures have been made to understand the challenge of internet connection reliability related to social determinants and online learning. Among these were the provision of internet devices for students at the university being studied (Capistrano, 2020).

Significant findings such as the negative relationship between living with family members and online learning readiness, bring to light the implications of the home environment with their readiness to learn with this medium. The study also found that there is no statistically significant relationship between COVID-19 Psychological Distress and Readiness for Online Learning. We affirm that Online Learning Readiness traits developed prior to COVID-19 persist despite pandemic-induced stressors. We suggest that a methodological pedagogy needs to be established to provide a comprehensive 
picture of learning both from learners' readiness and educational systems' competencies to move toward digital education.

The limitations and gaps of the study which will need to guide the focus of future research are both in the constructs being measured and the methods of the study. From a construct level the following are the gaps: First, the construct of psychological distress to be framed within educational systems and processes during COVID-19 was not established. Factors like boredom and lack of motivation among students due to the lack of meaningful verbal communication in online learning (Irawan et al., 2020) were not explored. Secondly, the long-term effect of trauma brought about by COVID-19 was also not investigated considering that there is a strong evidence of negative correlation between trauma and cognitive functioning (Mougrabi-Large \& Zhou, 2020). Third, the lack of identifying the history of problematic internet use (PIU) and the role this plays in online learning. Evidence shows that there is a high incidence of problematic use of the internet among young people (Mamun et al., 2020). And finally, when the idea of online learning was introduced, there was a lack of pedagogical approaches and principles of digital education due to the rapid move to online learning (Crawford et al., 2020). Thus, the construct of online learning and the readiness of learners should be based on such pedagogies.

In terms of methodology, given that the study had limited sample size and a nonprobability sampling technique, future studies may need to increase the generalizability of their findings. As more colleges adopt e-learning initiatives, it is recommended that these colleges be incorporated into the sampling pool to reflect greater variation. Another recommendation would be to utilize other data gathering platforms such as telephone, mail-in, or other forms of offline surveying. This would reduce bias that may be oriented towards those who already have the resources for online learning and online platforms for mental health management. While much of the country's education sector moves towards virtual platforms, leaders doubt the efficacy of this platform. (Modesto, 2020). Thus, those with limited access to the internet must also be reached out to ascertain e-learning readiness and their mental health.

\section{Recommendations}

The increased demand for online learning along with the unique stressors brought about by the pandemic present opportunities for research. Future studies may thus elaborate on how socioeconomic factors may have a role on the experiences of students' online learning. Specifically, researchers may want to conduct quantitative studies with a larger sample size. Furthermore, those interested in the students' experience may utilize a mixed methodology to suit the research agenda. As mentioned in the limitations of the present study, opportunities have opened to looking at the impact of social determinants of health on the psychological health of students.

The second recommendation of the authors is for stakeholders to consider the students' socioeconomic circumstances in assessing for their psychological health and learning readiness. While the present study does not provide for evidence showing the influence of SDH on the two, teachers and administrators may still consider these as points of interest. Mental health breaks, adjustments to school requirements, and other concrete actions that affirm the circumstances of the students must be balanced with the schools' agenda. 


\section{Plan for Research Dissemination and Utilization}

The findings of the pilot study were presented to undergraduate students of Ateneo de Davao's Psychology Department through an online video conference event on June 12, 2020. The pilot study was also cited as unpublished research in an international video conference event (Future of Education Conference) held last October 28, 2020. The university's Psychology Department also received a copy for their reference. Lastly, participants who wished to receive a copy of the findings were granted a request.

\section{Funding Acknowledgement Statement}

The study was personally funded by the authors.

\section{References}

Abiad, A., Arao, R. M., \& Dagli, S. (2020). The economic impact of the COVID-19 outbreak on developing Asia (ADB Briefs No. 128). Asian Development Bank. https://doi.org/10.22617/BRF200096

Alipio, M. M. (2020). Education during COVID-19 era: Are learners in a less-economically developed country ready for e-learning? ZBW - Leibniz Information Centre for Economics, Kiel, Hamburg. https://doi.org/10.2139/ssm.3586311

Alkorashy, H. A. E., \& Assi, N. E. A. (2016). Readiness for self-directed learning among bachelor nursing students in Saudi Arabia: A survey-based study. International Journal of Nursing Education and Research, 4(2), 187-194.

Bandura, A. (1982). Self-efficacy mechanism in human agency. American Psychologist, 37(2), 122147. https://doi.org/10.1037/0003-066X.37.2.122

Becerra, M. B., \& Becerra, B. J. (2020). Psychological distress among college students: Role of food insecurity and other social determinants of mental health. International Journal of Environmental Research and Public Health, 17(11), 4118. https://doi.org/10.3390/ijerph17114118

Callo, E. C., \& Yazon, A. D. (2020). Exploring the factors influencing the readiness of faculty and students on online teaching and learning as an alternative delivery mode for the new normal. Universal Journal of Educational Research, 8(8), 3509-3518. https://doi.org/10.13189/ujer.2020.080826

Capistrano, Z. (2020, April 27). Ateneo de Davao to provide 155 Apple iPads for students' online learning. https://mb.com.ph/2020/04/27/ateneo-de-davao-to-provide-155-apple-ipads-forstudents-online-learning/

Chen, Y., Jones, C., \& Dunse, N. (2021). Coronavirus disease 2019 (COVID-19) and psychological distress in China: Does neighbourhood matter? Science of the Total Environment, 759, 144203. https://doi.org/10.1016/j.scitotenv.2020.144203

Clemen, I. G., Ali, H., Abdulmadid, A.-N., \& Jabbar, J. H. (2021). Education during COVID-19 era: Readiness of students in a less-economically developed country for e-learning. IMCC Journal of Science, 1(1), 94-101.

Cohen, J., \& Kupferschmidt, K. (2020). Countries test tactics in 'war' against COVID-19. Science, 367(6484), 1287 LP - 1288. https://doi.org/10.1126/science.367.6484.1287 
Commission on Higher Education (2020). CHED COVID-19 Advisory No. 3. https://ched.gov.ph/wpcontent/uploads/CHED-COVID-2019-Advisory-No.-3.pdf

Craw, J. (2020). Statistic of the month: How much time do students spend in school? NCEE. https://ncee.org/2018/02/statistic-of-the-month-how-much-time-do-students-spend-in-school/

Crawford, J., Butler-Henderson, K., Rudolph, J., Malkawi, B., Glowatz, M., Burton, R., . . Lam, S. (2020). COVID-19: 20 countries' higher education intra-period digital pedagogy responses. Journal of Applied Learning \& Teaching, 3(1). https://doi.org/10.37074/jalt.2020.3.1.7

Dellosa, R. (2020, July 28). Interview by GMA Public Affairs [Television broadcast]. Manila: GMA Digital.

Duncan, E. (2020, March 27). NSW domestic violence support groups warn coronavirus isolation is prompting surge in demand for services. ABC News Australia. https://www.abc.net.au/news/2020-03-27/coronavirus-domestic-family-violence-covid-19-sur ge/12096988

Eccles, J. S., \& Wigfield, A. (2002). Motivational beliefs, values, and goals. Annual Review of Psychology, 53(1), 109-132. https://doi.org/10.1146/annurev.psych.53.100901.135153

Estira, K. L. A. (2020). Online distance learning readiness of business administration students in one state university in the Philippines. Journal of Critical Reviews, 7(12), 826-832. http://dx.doi.org/10.31838/jcr.07.12.14

Francis M. K., Wormington S.V., \& Hulleman, C. (2019). The costs of online learning: Examining differences in motivation and academic outcomes in online and face-to-face community college developmental mathematics courses. Frontiers in Psychology, 10, 2054. https://doi.org/10.3389/fpsyg.2019.02054

Hung, M. L., Chou, C., Chen, C. H., \& Own, Z. Y. (2010). Learner readiness for online learning: Scale development and student perceptions. Computers \& Education, 55(3), 1080-1090. https://www.learntechlib.org/p/66872/

Irawan, A., Dwisona, D., \& Lestari, M. (2020). Psychological impacts of students on online learning during the pandemic COVID-19. Konseli. https://doi.org/10.24042/kons.v7i1.6389

Kanter, J., \& Manbeck, K. (2020, May 12). After COVID-19 is beaten back, doctors warn of a new challenge that awaits. Inverse. https://www.inverse.com/mind-body/post-covid-19-depression

Kemp, S. (2020). Digital 2020: The Philippines. https://datareportal.com/reports/digital-2020philippines

Kim, K.-J., \& Frick, T. W. (2011). Changes in student motivation during online learning. Journal of Educational Computing Research, 44(1), 1-23. https://doi.org/10.2190/ec.44.1.a

Lai, J., Ma, S., Wang, Y., Cai, Z., Hu, J., Wei, N., Wu, J., Du, H., Chen, T., Li, R., Tan, H., Kang, L., Yao, L., Hwang, M., Wang, H., Wang, G., Liu, Z., \& Hu, S. (2020). Factors associated with mental health outcomes among health care workers exposed to coronavirus disease 2019. JAMA Network Open, 3(3), e203976. https://doi.org/10.1001/jamanetworkopen.2020.3976

Mamun, M. A., Hossain, M. S., Moonajilin, M. S., Masud, M. T., Misti, J. M., \& Griffiths, M. D. (2020). Does loneliness, self-esteem and psychological distress correlate with problematic internet use? A Bangladeshi survey study. Asia-Pacific Psychiatry, 12(2), e12386.https://doi.org/10.1111/appy.12386

Marcial, D. E., Caballero, R. D. B., Rendal, J. B., \& Patrimonio, G. A. (2015). "I am offline": Measuring barriers to open online learning in the Philippines. Information Technologies and Learning Tools, 45(1), 28-41. https://doi.org/10.33407/itlt.v45i1.1170 
Mateo, J. (2020, May 13). Summer classes shift to distance learning. The Philippine Star. https://www.philstar.com/headlines/2020/05/13/2013623/summer-classes-shift-distancelearning

Mazza, C., Ricci, E., Biondi, S., Colasanti, M., Ferracuti, S., Napoli, C., \& Roma, P. (2020). A nationwide survey of psychological distress among Italian people during the COVID-19 pandemic: Immediate psychological responses and associated factors. International Journal of Environmental Research and Public Health, 17(9), 3165. https://doi.org/10.3390/ijerph17093165

Medina, B. T. G. (2001). The Filipino family. University of the Philippines Press.

Mendoza, L. E. (2020, May 17). Mendoza: Bracing the 'new normal'. SunStar Philippines. https://www.sunstar.com.ph/article/1856729

Mental Health Foundation. (2020). The COVID-19 pandemic, financial inequality and mental health. https://www.mentalhealth.org.uk/our-work/research/coronavirus-mental-healthpandemic/covid-19-inequality-briefing

Modesto, C. A. (2020, June 5). Are PH schools ready for virtual learning? Duterte has doubts. https://www.cnnphilippines.com/news/2020/6/5/duterte-online-learning.html

Montano, R. L. T., \& Acebes, K. M. L. (2020). Covid stress predicts depression, anxiety and stress symptoms of Filipino respondents. International Journal of Research in Business and Social Science (2147-4478), 9(4), 78-103. https://doi.org/10.20525/ijrbs.v9i4.773

Mougrabi-Large, R., \& Zhou, Z. (2020). The effects of war and trauma on learning and cognition: The case of Palestinian children. In C. Maykel \& M. A. Bray (Eds.), Promoting mind-body health in schools: Interventions for mental health professionals (pp. 387-403). American Psychological Association. https://doi.org/10.1037/0000157-026

Myer, L., Stein, D. J., Grimsrud, A., Seedat, S., \& Williams, D. R. (2008). Social determinants of psychological distress in a nationally-representative sample of South African adults. Social science \& medicine, 66(8), 1828-1840. https://doi.org/10.1016/j.socscimed.2008.01.025

Ng, S. F., \& Confessore, G. J. (2015). Learner autonomy and selected demographic characteristics as they relate to life satisfaction among older adults in Malaysia. Educational Gerontology, 41(5), 361-372.

Noguchi, Y. (2020, July 4). Why some young people fear social isolation more than COVID-19. NPR. https://www.npr.org/sections/health-shots/2020/07/04/885546281/why-some-young-peoplefear-social-isolation-more-than-covid-19

Peeri , N. C., Shrestha, N., Rahman, M. S., Zaki, R., Tan, Z., Bibi, S., Baghbanzadeh, M., Aghamohammadi, N., Zhang, W., \& Haque, U. (2020). The SARS, MERS and novel coronavirus (COVID-19) epidemics, the newest and biggest global health threats: what lessons have we learned? International Journal of Epidemiology, 2020, 1-10. https://doi.org/10.1093/ije/dyaa033

Philippine Statistics Authority. (2015). Highlights of the Philippine population 2015 Census of Population. $\quad$ https://psa.gov.ph/content/highlights-philippine-population-2015-censuspopulation

Qiu, J., Shen, B., Zhao, M., Wang, Z., Xie, B., \& Xu, Y. (2020). A nationwide survey of psychological distress among Chinese people in the COVID-19 epidemic: Implications and policy recommendations. General Psychiatry,33(2). https://doi.org/10.1136/gpsych-2020100213

Razai, M. (2020). Mitigating the psychological effects of social isolation during the COVID-19 pandemic. British Medical Journal, 369, m1904. https://doi.org/10.1136/bmj.m1904 
Sharp, J., \& Theiler, S. (2018). A review of psychological distress among university students: Pervasiveness, implications and potential points of intervention. International Journal for the Advancement of Counselling, 40(3), 193-212. https://doi.org/10.1007/s10447-018-9321-7

Silva, M., Loureiro, A., \& Cardoso, G. (2016). Social determinants of mental health: A review of the evidence. The European Journal of Psychiatry, 30(4), 259-292.

Sohrabi, C., Alsafi, Z., O’Neill, N., Khan, M., Kerwan, A., Al-Jabir, A., Iosifidis, C., \& Agha, R. (2020). World Health Organization declares global emergency: A review of the 2019 novel coronavirus (COVID-19). International Journal of Surgery, 76, 71-76. https://doi.org/10.1016/j.ijsu.2020.02.034

Solar, O., \& Irwin, A. (2010). A conceptual framework for action on the social determinants of health (Social Determinants of Health Discussion Paper 2: Policy and Practice). World Health Organization.

Song, L. (2011). Social capital and psychological distress. Journal of Health and Social Behavior, 52(4), 478-492.

Tee, M. L., Tee, C. A., Anlacan, J. P., Aligam, K. J. G., Reyes, P. W. C., Kuruchittham, V., \& Ho, R. C. (2020). Psychological impact of COVID-19 pandemic in the Philippines. Journal of Affective Disorders, 277, 379-391. https://doi.org/10.1016/j.jad.2020.08.043

Toquero, C. M. (2020). Challenges and opportunities for higher education amid the COVID-19 pandemic: The Philippine context. Pedagogical Research, 5(4), em0063. https://doi.org/10.29333/pr/7947

United Nations Educational, Scientific and Cultural Organization. (2020). COVID-19 educational disruption and response. https://en.unesco.org/covid19/educationresponse

Usher, K., Bhullar, N., Durkin, J., Gyamfi, N., \& Jackson, D. (2020). Family violence and COVID19: Increased vulnerability and reduced options for support. International Journal of Mental Health Nursing, 29(4), 549-552. https://doi.org/10.1111/inm.12735

Van Lancker, W., \& Parolin, Z. (2020). COVID-19, school closures, and child poverty: A social crisis in the making. The Lancet Public Health, 5(5), e243-e244.

World Health Organization. (2020a). Mental health \& COVID-19. https://www.who.int/teams/mentalhealth-and-substance-use/covid-19

World Health Organization. (2020b). WHO announces COVID-19 outbreak a pandemic. http://www.euro.who.int/en/health-topics/health-emergencies/coronavirus-covid19/news/news/2020/3/who-announces-covid-19-outbreak-a-pandemic

Yáñez, J. A., Afshar Jahanshahi, A., Alvarez-Risco, A., Li, J., \& Zhang, S. X. (2020). Anxiety, distress, and turnover intention of healthcare workers in Peru by their distance to the epicenter during the COVID-19 crisis. The American Journal of Tropical Medicine and Hygiene, 103, 1614-1620. https://doi.org/10.4269/ajtmh.20-0800

Zhang, S. X., Huang, H., \& Wei, F. (2020). Geographical distance to the epicenter of Covid-19 predicts the burnout of the working population: Ripple effect or typhoon eye effect? Psychiatry Research, 288, 112998. https://doi.org/10.1016/j.psychres.2020.112998

Zhang, J., Lu, H., Zeng, H., Zhang, S., Du, Q., Jiang, T., \& Du, B. (2020). The differential psychological distress of populations affected by the COVID-19 pandemic. Brain, Behavior, and Immunity, 87, 49-50. https://doi.org/10.1016/j.bbi.2020.04.031 